\title{
Phosphorylation of prebiotic precursors
}

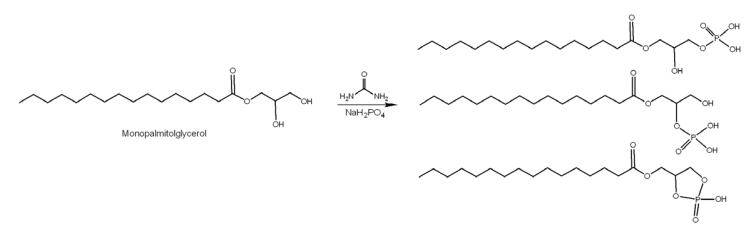

\author{
ANASTASIIA SHVETSOVA ${ }^{1}$, MICHELE FIORE ${ }^{2}$, PETER
} STRAZEWSKI $^{2}$ AND ISABELLE DANIEL ${ }^{3}$

${ }^{1}$ Université de Lyon - Labex LIO

${ }^{2}$ Université de Lyon, Claude Bernard Lyon 1

${ }^{3}$ Laboratoire de géologie de Lyon UMR 5276, Université Lyon1

- Ens de Lyon - CNRS

Presenting Author: anastasiia.shvetsova@univ-lyon1.fr

Phosphorus is an essential element for biomolecules such as nucleic acids, the energy-carrying molecule ATP and phospholipids [1]. Their formation includes a mandatory phosphorylation step, that requires a condensing agent like plausibly prebiotic urea for the phosphorylation reactions to be reasonably efficient under ambient pressure and temperature [2]. To increase our knowledge on this reaction we tested laboratory methods for obtaining phosphorylation products in dry conditions by varying the phosphorus source, the reaction temperature and using prebiotic alcohols as promising candidates for membranogenic compounds (Fig. 1) [3,4]. We will present several nitrogen-containing compounds similar to urea that were investigated to obtain the maximum yield of phosphorylated products, while taking into account the possibility of these reactions to occur on the early Earth. The next step is to include natural phosphate minerals, which usually have low solubilities and reactivities under normal conditions, and evaluate their potential for phosphorylation reactions under abiotic conditions [5].

[1] M. Pasek, M. Gull, B. Herschy, Phosphorylation on the early earth. Chemical Geology 2017, 475. 10.1016/j.chemgeo.2017.11.008

[2] M. Fiore, P. Strazewski, Prebiotic Lipidic Amphiphiles and Condensing Agents on the Early Earth. Life 2016, 6, 17. https://doi.org/10.3390/life6020017

[3] M. Gull; M. Pasek, The Role of Glycerol and Its Derivatives in the Biochemistry of Living Organisms, and Their Prebiotic Origin and Significance in the Evolution of Life. Catalysts 2021, 11, 86. https://doi.org/10.3390/catal11010086

[4] M. Fiore, W. Madanamoothoo, A. Berlioz-Barbier, O. Maniti, A. Girard-Egrot, R. Buchet, P. Strazewski, Giant vesicles from rehydrated crude mixtures containing unexpected mixtures of amphiphiles formed under plausibly prebiotic conditions. Org. Biomol. Chem. 2017, 15, 4231-4240. DOI: 10.1039/c7ob00708f

[5] J. Hao, A. Knoll, F. Huang, J. Schieber, R. Hazen, I. Daniel, Cycling phosphorus on the Archean Earth: Part II. Phosphorus limitation on primary production in Archean ecosystems, Geochimica et Cosmochimica Acta 2020, 280. https://doi.org/10.1016/j.gca.2020.04.005 